\title{
Investigation on electrical conductivity and hardness of 6xxx aluminum conductor alloys with different $\mathrm{Si}$ levels
}

\author{
Siamak Nikzad Khangholi ${ }^{1, *}$, Mousa Javidani ${ }^{1}$, Alexandre Maltais ${ }^{2}$ and X.-Grant Chen ${ }^{1}$ \\ ${ }^{1}$ Department of Applied Sciences, University of Quebec at Chicoutimi, Saguenay, QC, Canada, G7H 2B1 \\ ${ }^{2}$ Arvida Research and Development Centre, Rio Tinto Aluminum, Saguenay, QC, Canada, G7S 4K8
}

\begin{abstract}
The impact of $\mathrm{Si}$ levels on electrical conductivity (EC) and hardness in Al-Mg-Si 6xxx aluminum conductor alloys was studied at different aging times. Three experimental alloys with the $\mathrm{Si}$ levels of $0.4,0.66,0.89$ wt. $\%$ containing a constant $\mathrm{Mg}$ content of $0.65 \mathrm{wt} . \%$, designated as Si4, Si6, and $\mathrm{Si}$, were selected. It is found that the average peak hardness of Si4, Si6, and Si9 alloys were 114, 127 and $140 \mathrm{HV}$, respectively. The Si9 alloy with the highest Si level exhibited the highest peak hardness, which was consistent with the number density of strengthening precipitates. However, the EC of all studied alloys at peak aging was lower than the minimum required one (52.5\%IACS). The higher Si level in the alloy, the longer aging time required to enhance EC. The Si4, Si6, and $\mathrm{Si} 9$ alloys reached the minimum required EC after 3, 5 and $34 \mathrm{~h}$ aging time, of which the corresponding hardness was 103, 119 and $111 \mathrm{HV}$, respectively. Consequently, the Si6 alloy represented a better trade-off between EC and hardness among three studied alloys. The quantitative analyses of precipitates at peak aging and overaging states were carried out by a transmission electron microscope (TEM) investigation.
\end{abstract}

\section{Introduction}

In recent years, the application of Al-Mg-Si alloys (such as AA6101 and AA6201) in the electric transmission line are increasingly grown since they give a wide variety of the strength due to precipitation hardening along with the desired electrical conductivity [1, 2]. Aluminum conductors can be generally regrouped into two categories: aluminum conductor steel reinforced (ACSR) and all-aluminum alloy conductor (AAAC). In the ACSR, commercial pure aluminum alloys such as AA1350 alloy are widely used, of which the core consists of the steel to reinforce the structural function in power lines. To meet the requirement of high mechanical properties and good corrosion resistance, the AAAC, especially Al-Mg-Si 6xxx alloys, are mostly used in high voltage transmission lines because of their high strength [1-5].

Magnesium and silicon are known as the major alloying elements in Al-Mg-Si 6xxx alloys, making them age-hardenable alloys [6]. It was found that the various $\mathrm{Mg} / \mathrm{Si}$ ratios could affect the strength and electrical conductivity of Al-Mg-Si conductor alloys to a great extent [6-8]. In the coarse-grained structure, the excessive $\mathrm{Si}(1<\mathrm{Mg} / \mathrm{Si}<2)$ led to the higher hardness and strength with a slight decrease in EC $[6,7]$, while in the fine-grained structure it resulted in a higher EC owing to the grain boundary precipitates [7]. In general, the $\mathrm{Mg}$ excessive may not have a significant impact on strength, while affecting negatively EC [6].

Corresponding author: siamak.nikzad-khangholi1@uqac.ca
In general, precipitation hardening, work hardening, grain boundary strengthening, and solute solution strengthening are the main strengthening mechanisms in aluminum conductor alloys. However, in the metallurgical aspect, most parameters enhancing the strength of aluminum alloys tend to reduce their electrical conductivity. Therefore, the mechanical properties and electrical conductivity should be simultaneously taken into account in development of Al$\mathrm{Mg}-\mathrm{Si}$ conductor alloys [9]. To ensure the high performance of aluminum conductor alloys, the norms and regulations describing the design requirement have been established. For example, the minimum requirement of AA6201 alloy wires with the diameter between $3.25 \mathrm{~mm}$ and $4.75 \mathrm{~mm}$ for UTS and EC are $305 \mathrm{MPa}$ and $52.5 \% \mathrm{IACS}$, respectively $[5,10,11]$.

Considering that the $\mathrm{Mg} / \mathrm{Si}$ ratio of the $\beta^{\prime \prime}$ precipitates as a strengthening phase is one $[12,13]$, the effect of different $\mathrm{Si}$ levels relative to the $\mathrm{Mg} / \mathrm{Si}$ ratio of $\beta "$ on EC and hardness has been rarely studied. The aim of this study is to investigate the effect of various $\mathrm{Si}$ levels on EC and hardness. The underlying microstructures for balancing the electrical conductivity and hardness were explored by the quantitative analysis of strengthening precipitates.

\section{Experimental}

Three experimental alloys with the $\mathrm{Si}$ contents of 0.4 , $0.66,0.89$ wt. $\%$ and a constant $\mathrm{Mg}$ content of 0.65 wt. $\%$, 
designated as $\mathrm{Si} 4, \mathrm{Si} 6$, and $\mathrm{Si}$, were investigated in the present work, and their chemical compositions are listed in Table 1. The general wire fabrication process consists of casting, homogenization $\left(560{ }^{\circ} \mathrm{C}\right.$ for $\left.6 \mathrm{~h}\right)$, followed by hot rolling at $350-480{ }^{\circ} \mathrm{C}(74 \%$ area reduction $)$. The hotrolled sheets were machined into the square bars, after which a solution treatment at $540{ }^{\circ} \mathrm{C}$ for $2 \mathrm{~h}$ was applied. Afterwards, the cold wire drawing (area reduction of $50 \%$ ) for the final diameter of wires of $4.7 \mathrm{~mm}$ was conducted, followed by the artificial aging at $180{ }^{\circ} \mathrm{C}$ for different aging times. It was reported that $180{ }^{\circ} \mathrm{C}$ is an appropriate aging temperature to get a better optimization of strength and EC in Al-Mg-Si conductor alloys [14].

The electrical conductivity based on ASTM E1004 was measured via Sigmascope method with frequency of $480 \mathrm{kHz}$ at different aging times. Fifteen measurements were recorded and calculated as an average value. The microhardness tests were carried out with the force of 25 $\mathrm{g}$ and dwell time $20 \mathrm{~s}$, and the average value of eight measurements was reported. The intermetallic phases in three alloys were investigated using a scanning electron microscope equipped with energy dispersive spectroscopy (EDS). To characterize the strengthening precipitates, the TEM samples were taken from the drawn samples and prepared using the electropolishing technique. The characteristics of precipitates, such as their number density, were quantified using the method in Ref. [15].

\section{Results and Discussion}

Fig. 1a and $1 \mathrm{~b}$ show the microhardness and electrical conductivity (EC) of experimental alloys as a function of the aging times. The microhardness of the alloys first increased sharply to reach their peak values and then gradually decreased with increasing aging time. In general, the higher Si content, the higher microhardness is during entire aging period. The peak microhardness of Si4, Si6, and Si9 alloys are 114, 127 and $140 \mathrm{HV}$, respectively. However, the $\mathrm{EC}$ values of $\mathrm{Si} 4, \mathrm{Si}$, and $\mathrm{Si} 9$ alloys at the peak aging are 52.3, 49, and 47.5 $\%$ IACS, respectively, which are less than the minimum required EC (52.5\%IACS). Therefore, the aging time needs to be prolonged to enhance EC. It was found that the EC of the $\mathrm{Si} 4, \mathrm{Si} 6$, and $\mathrm{Si} 9$ alloys started to exceed $52.5 \%$ IACS after 3, 5, $34 \mathrm{~h}$, respectively. The corresponding microhardness values for $\mathrm{Si} 4, \mathrm{Si} 6$, and Si9 alloys are 103, 119 and $111 \mathrm{HV}$, respectively.

Fig. 1c shows the microhardness versus EC for the entire aging times, and Fig. 1d magnifies Fig. 1c to represent the microhardness versus EC above the required 52.5\%IACS. Results of Fig. 1c show that in the low EC range (44-51 \%IACS), the high Si alloy (Si9) exhibits the highest microhardness. However, with increasing $\mathrm{EC}$, the microhardness of the $\mathrm{Si} 6$ alloy exceeds the microhardness of the Si9 alloy. It can be seen in Fig. 1d, the Si6 alloy shows the highest hardness above the minimum required EC among three alloys, suggesting as an appropriate candidate for conductor applications provided the strength is taken into account in the priority. However, with a further increase in aging time, the microhardness of the Si6 alloy sharply drops with an insignificant growth in EC, exhibiting a small window of high microhardness above the minimum required EC. Similarly, the $\mathrm{Si} 9$ alloy has the second highest hardness but shows a limited window of microhardness above $52.5 \% \mathrm{IACS}$. On the other hand, in the high EC range (54.5-55.5\%IACS), the Si4 alloy still shows a reasonably high strength (90-100 HV). Therefore, the low Si alloy ( $\mathrm{Si} 4)$ could be considered if the EC becomes the first priority in the design.

Fig. 2 shows the type and distribution of Fe-rich intermetallics after homogenization in the three alloys. In general, the type of intermetallics can be distinguished according to the $\mathrm{Fe} / \mathrm{Si}$ ratio and morphology $[16,17]$. The predominant Fe-rich intermetallics in the Si4 alloy are spherical/Chinese-script shaped $\alpha-\mathrm{Al}_{8} \mathrm{Fe}_{2} \mathrm{Si}$ (Fig. 2a), while rod-like $\beta-\mathrm{Al}_{5} \mathrm{FeSi}$ is the dominant $\mathrm{Fe}$-rich intermetallics in the $\mathrm{Si} 6$ and $\mathrm{Si} 9$ alloys, as displayed in Fig. $2 b$ and c. Fig. $2 d$ shows the image analysis results of the distribution of Fe-rich intermetallics in the three alloys. The type and distribution of the intermetallics in those alloys could be correlated to the $\mathrm{Fe} / \mathrm{Si}$ ratio of the alloys and homogenization temperature [18]. Since the $\beta-\mathrm{Al}_{5} \mathrm{FeSi}$ intermetallics consume more $\mathrm{Si}$ compared to $\alpha-\mathrm{Al}_{8} \mathrm{Fe}_{2} \mathrm{Si}$ intermetallics [19], it could be generally expected that the presence of $\beta$ intermetallics slightly enhances the electrical conductivity and reduces the precipitation degree due to the Si solute extraction from the matrix. In addition, the $\beta$ intermetallics have more stress concentration due to their plate-like morphologies relative to $\alpha$ intermettalics [20], affecting the strength. In reality, the volume fractions of the Fe-rich intermetallics in all three alloys are quite low (less than 0.5\%). Therefore, it is reasonable to expect that the Fe-rich intermetallics have insignificant effects on both strength and EC of experimental alloys.

Fig. 3 displays bright field TEM images of the precipitate distribution at the peak aging for three alloys. As mentioned above, the peak aging conditions are the $\mathrm{Si} 4$ alloy at $2 \mathrm{~h}$ (Fig. 3a), the Si6 alloy at $1 \mathrm{~h}$ (Fig. 3b), and the Si9 alloy at $1 \mathrm{~h}$ (Fig. $3 \mathrm{c}$ ). The density numbers of precipitates are shown in Fig. 3d, indicating that the average density number of precipitates increased with the Si level. Fig.3e displays the precipitate length and inter-precipitate spacing for three alloys at peak-aged states. Based on Fig.3e, the average precipitate lengths for Si4-2h, Si6-1h, and Si9-1h alloys were approximately $50 \mathrm{~nm}$. It was reported that the majority of precipitates were identified as $\beta^{\prime}$ precipitates since the cold drawing could suppress the formation of $\beta$ " phases $[21,22]$. It is found that the Si9 alloy exhibited the highest number density of precipitates, which corresponds well with the highest microhardness at peak aging. On the other hand, the Si4 alloy possesses the lowest number density, resulting in the lowest 
microhardness at peak aging (Fig. 1a). It stems from the fact that $\mathrm{Si}$ addition increases the number of the clusters in the early aging, promoting the precipitation of the strengthening phase $[6,23]$. Moreover, the $\mathrm{Si}_{2}$ columns were observed in the core of GP zones and the subsequent precipitates [24], showing the key role of $\mathrm{Si}$ in precipitation. Based on Fig.3e and Fig.1a, the interprecipitate spacing is inversely proportional to peak- hardness, meaning that Si-excessive alloys (Si6-1h and $\mathrm{Si} 9-1 \mathrm{~h})$ with a smaller inter-precipitate spacing are more resistant against dislocation movement. On the other hand, a shorter inter-precipitate spacing causes more electrical resistivity [25], especially in Si6-1h and Si9-1h alloys compared to Si4-2h alloy. Therefore, lower EC in peak-aged condition for Si6 and $\mathrm{Si} 9$ alloys could mainly result from both solute (especially $\mathrm{Si}$ ) and precipitates.

Table 1 Chemical compositions of Al-Mg-Si conductor alloys with different Si levels

\begin{tabular}{|c|c|c|c|c|c|}
\hline \multirow{2}{*}{ Alloys } & \multicolumn{4}{|c|}{ Compositions (wt.\%) } & \multirow{2}{*}{$\begin{array}{c}\mathrm{Mg} / \mathrm{Si} \\
\text { (at.\%) }\end{array}$} \\
\cline { 2 - 5 } & $\mathrm{Mg}$ & $\mathrm{Si}$ & $\mathrm{Fe}$ & $\mathrm{Al}$ & 1.94 \\
\hline $\mathrm{Si} 4$ & 0.67 & $\mathbf{0 . 4}$ & 0.09 & Bal. & 1.15 \\
\hline Si 6 & 0.66 & $\mathbf{0 . 6 6}$ & 0.13 & Bal. & 1.86 \\
\hline Si 9 & 0.68 & $\mathbf{0 . 8 9}$ & 0.10 & Bal. & 0.86 \\
\hline
\end{tabular}
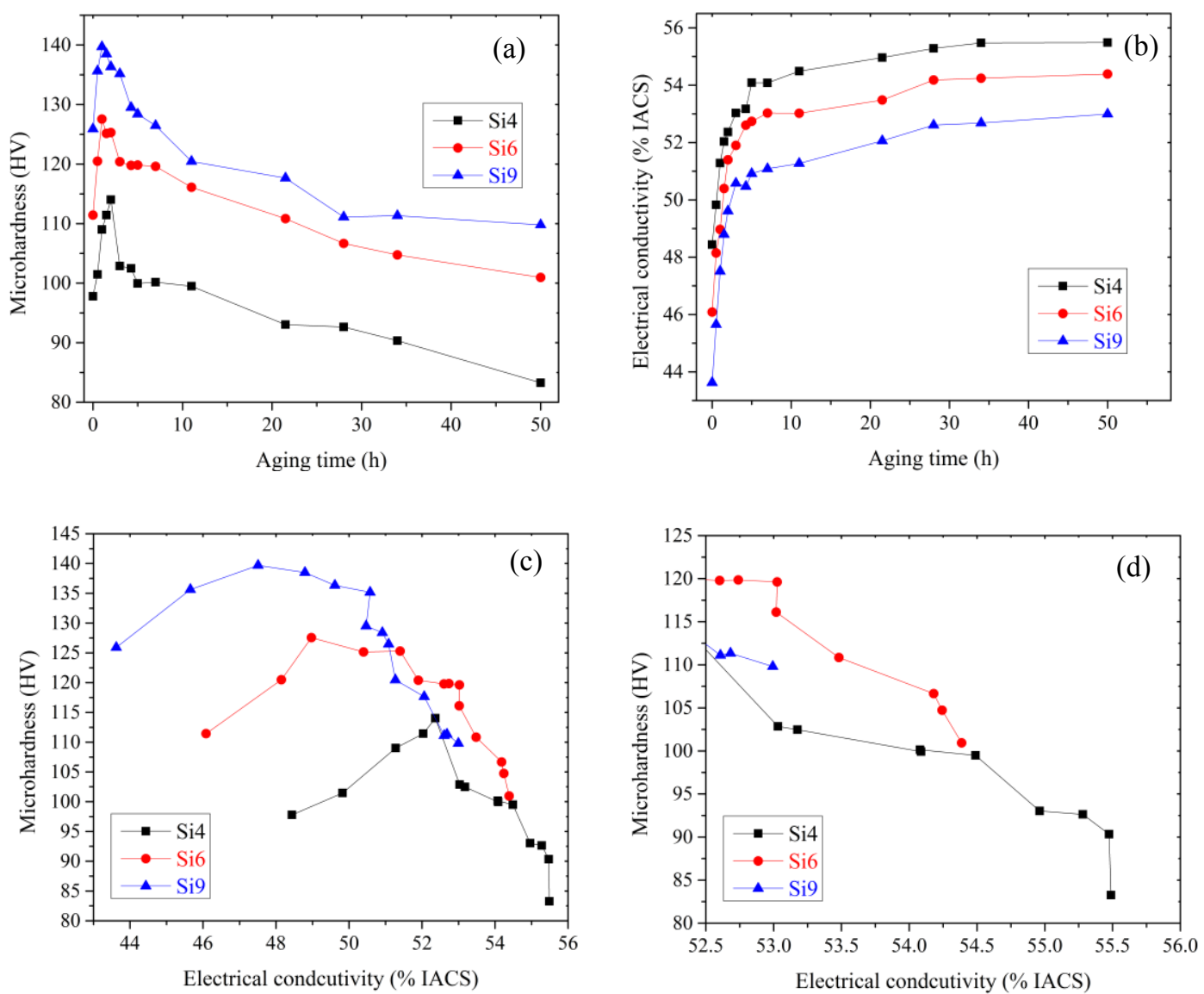

Figure 1 (a) Microhardness and (b) electrical conductivity as a function of the aging time at $180{ }^{\circ} \mathrm{C}$; (c) microhardness versus EC over entire aging times and (d) microhardness versus EC above the minimum required $52.5 \%$ IACS 

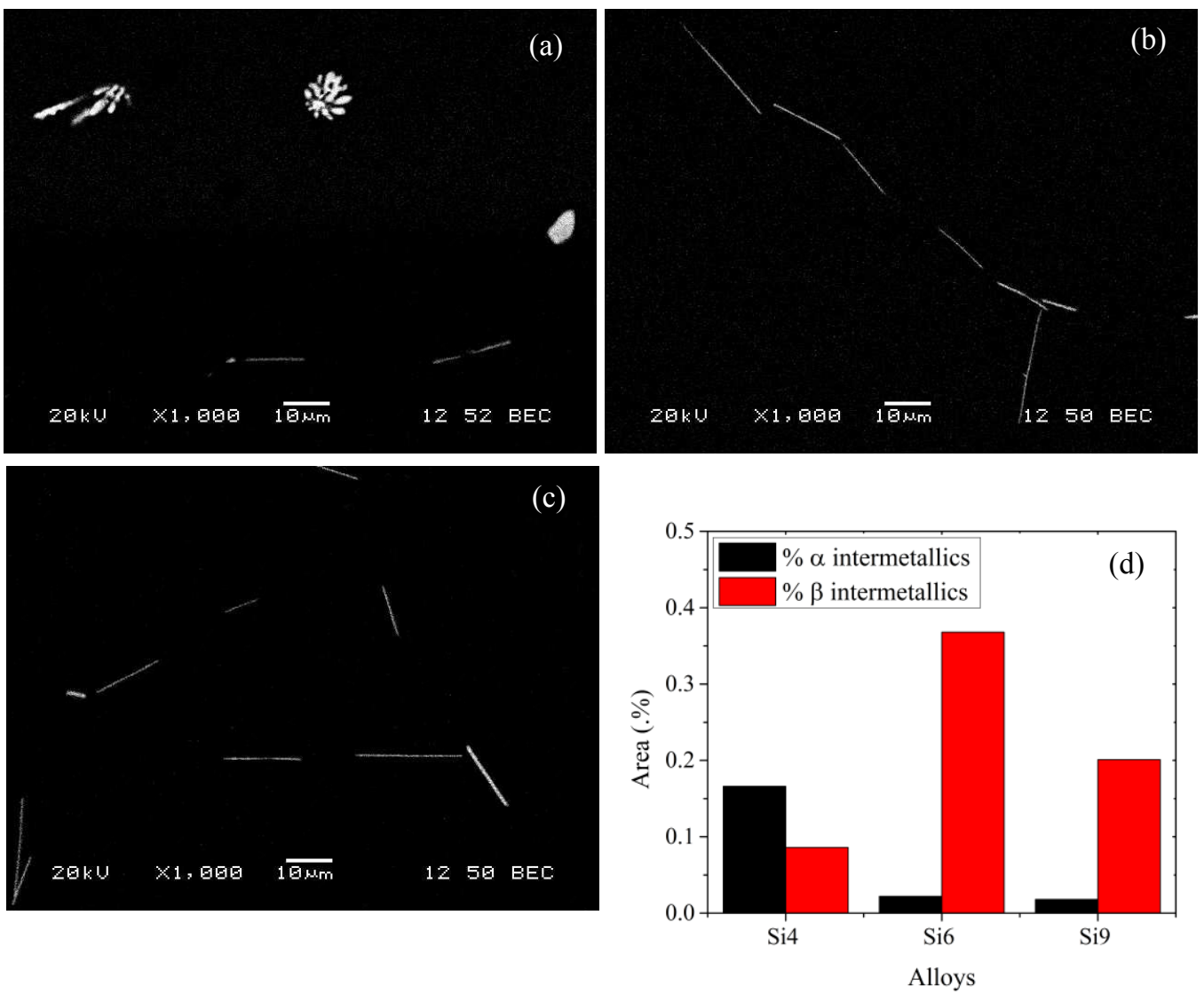

Figure 2 Distribution of Fe-rich intermetallics after homogenization in (a) Si4 (b) Si6 (c) Si9 alloys; (d) the area percentage of Fe-rich intermetallics in three alloys

As mentioned earlier, the $\mathrm{Si} 4, \mathrm{Si} 6$, and $\mathrm{Si} 9$ alloys met the minimum required $\mathrm{EC}$ after 3, 5, and $34 \mathrm{~h}$ aging, respectively. Obviously, with an increase in Si levels, the aging time has to be largely increased to enhance the EC, which causes the microstructure and hardness changes. The different aging times to reach the required $\mathrm{EC}$ in the experimental alloys could be attributed to the different $\mathrm{Si}$ solute levels in the aluminum matrix. Fig 4 displays the precipitates of Si4 alloy at $3 \mathrm{~h}$, Si6 alloy at $5 \mathrm{~h}$, and $\mathrm{Si} 9$ alloy at $34 \mathrm{~h}$ aging. Fig. $4 \mathrm{~d}$ shows the number density of precipitates, and Fig. 4e displays the precipitate length and inter-precipitate spacing at the corresponding aging times for three alloys. Measurements on the TEM images (Fig. 4e) reveal that the average precipitate lengths for Si4-3h, Si6-5h, and Si9-34h alloys were around 60,80 , and $170 \mathrm{~nm}$, respectively. Therefore, it can be identified that the Si9-34h alloys were subjected to more precipitate coarsening to reach the required $\mathrm{EC}$ in relation to Si4-3h and Si6-5h. Compared Fig. 3d with Fig. $4 d$, it could be seen that the number density of the precipitates in the Si9-34h alloy significantly drops after prolonged aging to meet the required $\mathrm{EC}$, resulting in a remarkable reduction of the strengthening effect (Fig. 1d). The Si6-5h alloy exhibited the highest number density of precipitate among three alloys, thereby showing the highest hardness. The number density of precipitates decreases from Si6-5h to Si4-3h and further to $\mathrm{Si} 9-34 \mathrm{~h}$ alloys after reaching the minimum required EC. Based on Fig. 4e, the Si9-34h alloy has the largest inter-precipitate spacing, suggesting that the electrical resistivity from precipitates greatly decreased. Therefore, electrical resistivity in Si9-34h alloys mainly comes from solutes (especially $\mathrm{Si}$ ).

It is worth mentioning that the $\mathrm{Si} 9$ alloy after $34 \mathrm{~h}$ aging showed the higher hardness relative to the $\mathrm{Si} 4$ alloy after $3 \mathrm{~h}$ aging (Fig. 1d), although its number density of precipitates is less than the Si4 alloy (Fig. 4d). In general, the precipitation hardening plays a primary role in controlling the strength for the heat-treatable aluminum alloys. However, the other strengthening mechanisms such as strain hardening and solid solution strengthening during wire drawing process can also make a remarkably contribution to the alloy strength. It could be deduced that both strain hardening and solid solution strengthening in the $\mathrm{Si} 9$ alloy are presumably higher than those in the Si4 alloy owing to its high $\mathrm{Si}$ level. 

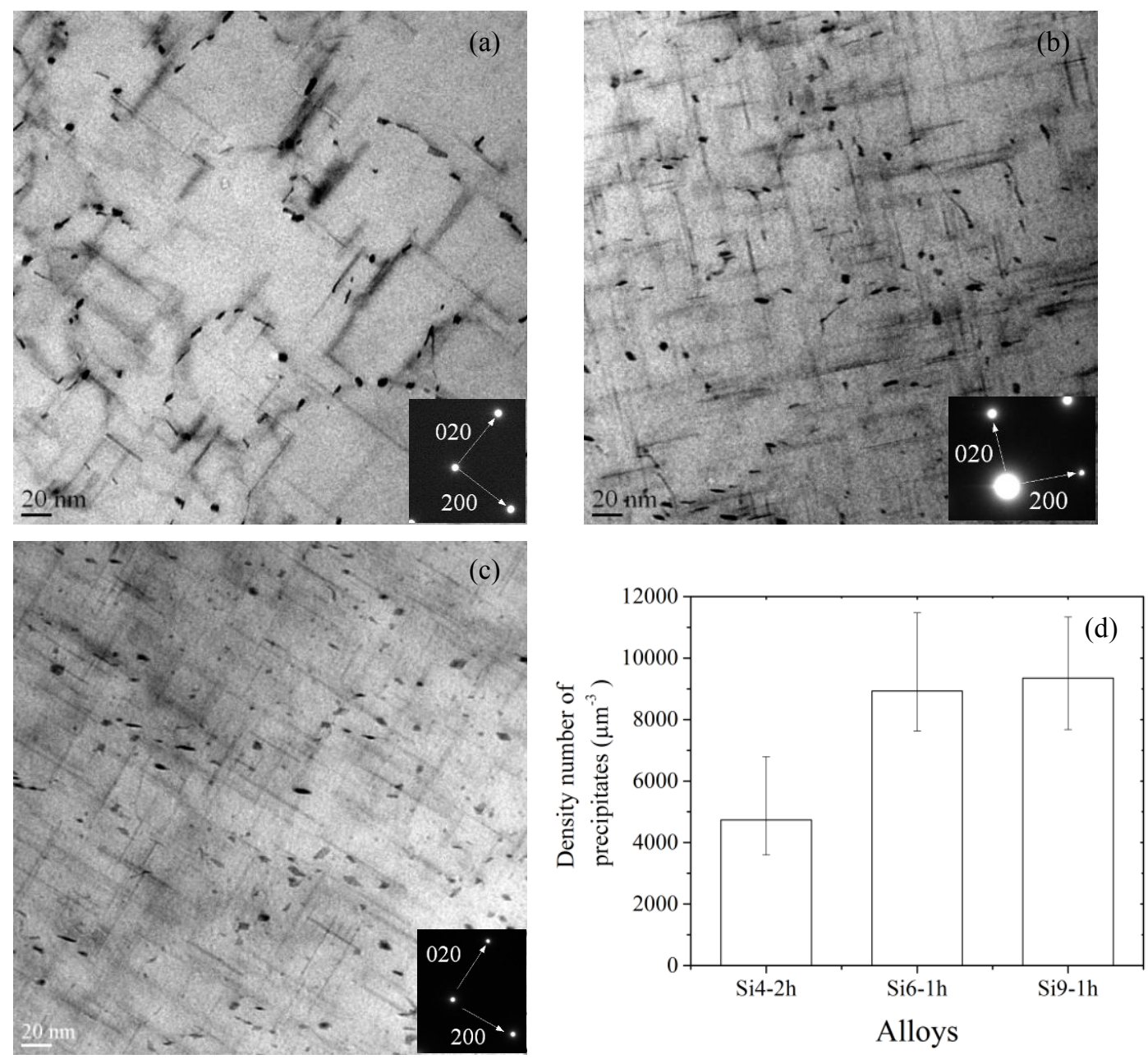

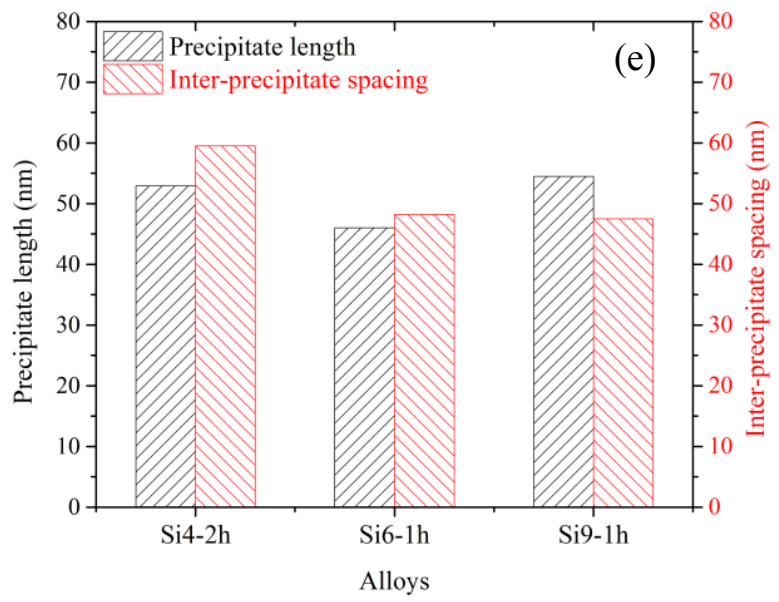

Figure 3 Precipitate distribution at peak aging state for (a) Si4 alloy after 2h (b) Si6 alloy after 1h (c) Si9 alloy after $1 \mathrm{~h}$ (aging at $180^{\circ} \mathrm{C}$ ); (d) the average number density of precipitates for three alloys; (e) the mean precipitate length and inter-precipitate spacing for three alloys 

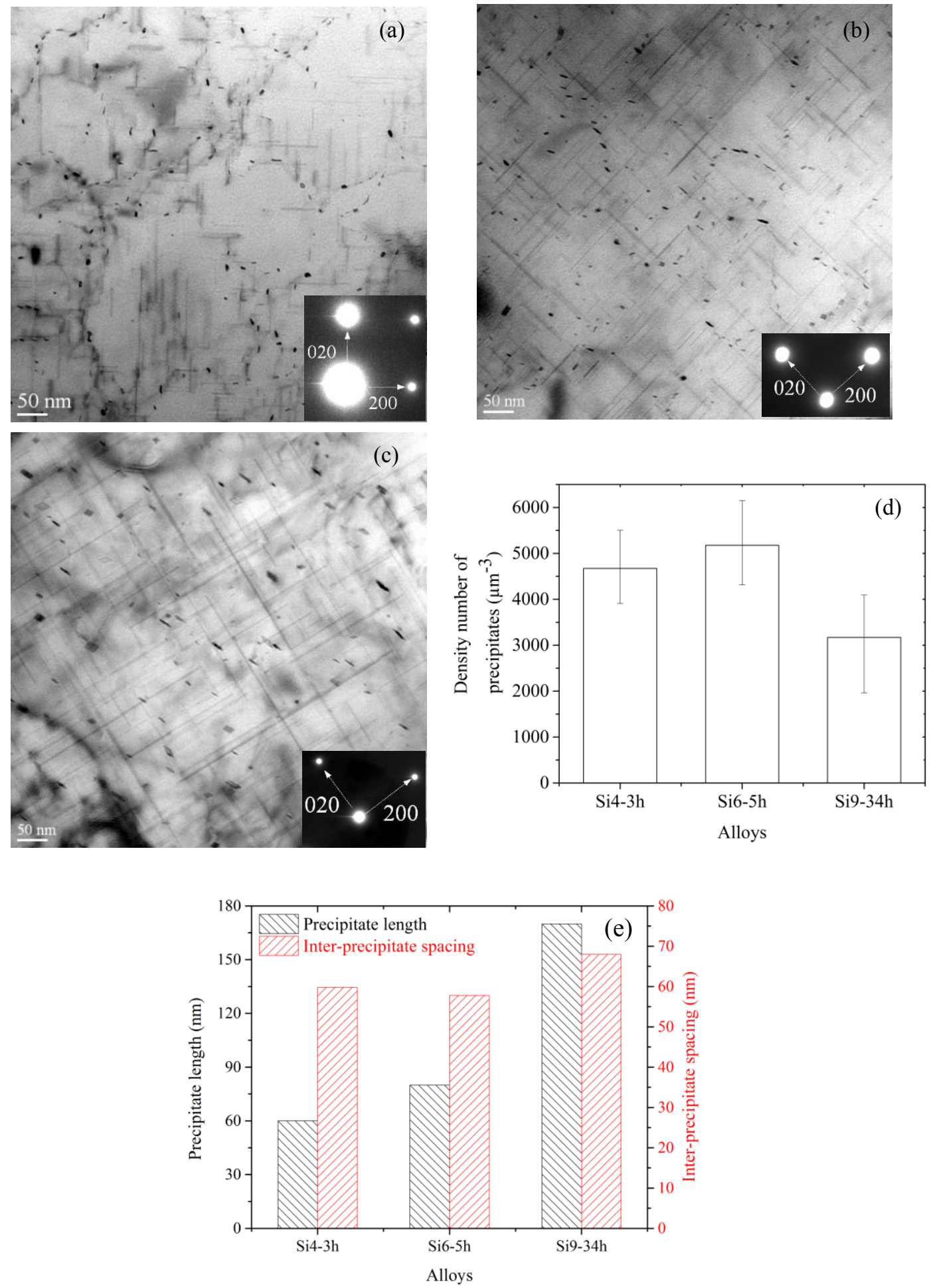

Figure 4 Precipitate distribution for (a) Si4 alloy after $3 \mathrm{~h}$ (b) Si6 alloy after 5h (c) Si9 alloy after $34 \mathrm{~h}$ aging at $180^{\circ} \mathrm{C}$; (d) the corresponding number density of precipitates for three alloys; (e) the mean precipitate length and inter-precipitate spacing for three alloys

\section{Conclusions}

1. The peak hardness of the Al-Mg-Si conductor alloys increased with Si levels irrespective of the electrical conductivity, mainly resulting from precipitation hardening of nanoscale precipitates.

2. Longer aging times required with increasing $\mathrm{Si}$ levels in Al-Mg-Si conductor alloys, especially in the $\mathrm{Si}$-excessive alloy $(\mathrm{Si} 9)$ to reach the minimum 
required EC. The hardness of the Si9 alloy sharply decreased from the peak aging to the prolonged overaging at which the minimum required EC reaches, showing a limited window of hardness above $52.5 \%$ IACS.

3. The Si6 alloy after $5 \mathrm{~h}$ aging showed the highest hardness above the minimum required EC. Its corresponding number density of precipitates was considerably higher than other two alloys above $52.5 \%$ IACS. Owing to its better trade-off between EC and hardness, the Si6 alloy can be considered as an appropriate candidate for aluminum conductor applications.

4. The Si9 alloy at $34 \mathrm{~h}$ aging exhibited the lowest number density of precipitates but still has higher hardness than the Si4 alloy at $3 \mathrm{~h}$ aging, suggesting the other strengthening mechanisms such as strain hardening and solid solution strengthening during wire drawing process can also make a remarkable contribution to the alloy strength.

\section{Acknowledgments}

The authors would like to acknowledge the financial support of the Natural Sciences and Engineering Research Council of Canada (NSERC) and Rio Tinto Aluminum through the Research Chair in the Metallurgy of Aluminum Transformation at University of Quebec at Chicoutimi.

\section{References}

[1] S. Karabay, Materials \& Design, 27, 821-832, (2006).

[2] S. Karabay, Materials \& Design, 29, 1364-1375, (2008).

[3] M. Iraizoz, N. Rossello, M. Amado, Light Metals 2015, Springer International Publishing, Cham, 183-187, (2016).

[4] F.U. Flores, D.N. Seidman, D.C. Dunand, N.Q. Vo, , Light Metals 2018, 247-251, (2018).

[5] M.G. E. Cervantes, J. A. Ramos, S.A. Montes, Mater. Res. Soc. Symp. Proc, 1275, 03-09, (2010).

[6] X. Xu, Z. Yang, Y. Ye, G. Wang, X. He, Materials Characterization, 119, 114-119, (2016).
[7] S. Jiang, R. Wang, Journal of Materials Science \& Technology, 35, 1354-1363, (2019).

[8] Y. Han, D. Shao, B.A. Chen, Z. Peng, Z.X. Zhu, Q. Zhang, X. Chen, G. Liu, X.M. Li, Journal of Materials Science, 52, 4445-4459, (2016).

[9] Q. Zhao, Z. Qian, X. Cui, Y. Wu, X. Liu, Journal of Alloys and Compounds, 666, 50-57, (2016).

[10] E. Standard, EN 50183. Conductors for overhead lines, aluminium magnesium silicon alloy wires, 2000.

[11] ASTM, Annual Book of ASTM Standards, Electrical Conductors, 2002.

[12] S.J.A. H.W. Zandbergen, J. Jansen, Science, 277, 1221-1225, (1997).

[13] H.W.Z. S.J. Andersen, J. Jansen, C. Træholt, U. Tundal, O. Reiso, Acta Materialia, 46, 3283-3298, (1998).

[14] G. Lin, Z. Zhang, H. Wang, K. Zhou, Y. Wei, Materials Science and Engineering: A, 650, 210-217, (2016)

[15] J. Kim, C. Daniel Marioara, R. Holmestad, E. Kobayashi, T. Sato, Materials Science and Engineering: A, 560, 154-162, (2013).

[16] Y. Wu, J. Xiong, R. Lai, X. Zhang, Z. Guo, Journal of Alloys and Compounds, 475, 332-338, (2009).

[17] Y. Birol, Journal of Materials Processing Technology, 148, 250-258, (2004).

[18] L.-z. Yan, Y.-a. Zhang, X.-w. Li, Z.-h. Li, F. Wang, H.-w. Liu, B.-q. Xiong, Transactions of Nonferrous Metals Society of China, 24, 939-945, (2014).

[19] M.H. Mulazimoglu, A. Zaluska, F. Paray, J.E. Gruzleski, Metallurgical and Materials Transactions A, 28, 1289-1295, (1997).

[20] M.H. Mulazimoglu, A. Zaluska, J.E. Gruzleski, F. Paray, Metallurgical and Materials Transactions A, 27, 929-936, (1996).

[21] H. Nemour, D. Mourad Ibrahim, A. Triki, Journal of Thermal Analysis and Calorimetry, 123, 19-26, (2015).

[22] K. Teichmann, C.D. Marioara, S.J. Andersen, K.O. Pedersen, S. Gulbrandsen-Dahl, M. Kolar, R. Holmestad, K. Marthinsen, Philosophical Magazine, 91, 3744-3754, (2011).

[23] C.D. Marioara, S.J. Andersen, H.W. Zandbergen, R. Holmestad, Metallurgical and Materials Transactions A, 36, 691-702, (2005).

[24] J.H. Chen, E. Costan, M.A. van Huis, Q. Xu, H.W. Zandbergen, Science, 312, 416-419, (2006).

[25] B. Raeisinia, W.J. Poole, D.J. Lloyd, Materials Science and Engineering: A, 420, 245-249, (2006). 